\title{
Postoperative neuroleptic malignant syndrome. A case report
}

A case of postoperative neuroleptic malignant syndrome is presented. A healthy 23-year-old male underwen a shoulder repair under uneventul fentanyl, halothane, nitrous oxide and oxygen anaesthesia. He received droperidol $5 \mathrm{mg} I \mathrm{~V}$ and metoclopramide $10 \mathrm{mg} I V$ intraoperatively to prevent postoperative nausea. Postoperatively, the patient developed autonomic instability, fever and generalized muscle rigidity. His level of consciousness was depressed. These findings were comsistent with the diagnosis of neuroleptic malignamt syndrome. The supportive treatment of the patient included active cooling measures, muscle relaxation and mechanical ventilation. The ability of anti-dropaminergic agents, including metoclopramide and droperidol, to precipitate the neuroleptic malignant syndrome is discussed. Treatment of the neuroleptic malignant syndrome is briefly discussed.

Neuroleptic agents, commonly referred to as major tranquilizers, have come into prominent use in modern psychiatry. Droperidol, a butyrophenone, is also frequently used by anaesthetists as an anaesthetic adjunct. While the extrapyramidal and cardiovascular effects of neuroleptics are well known, recent interest has focused upon their ability to cause an uncommon disorder, the neuroleptic malignant syndrome (NMS). The major features of NMS include fluctuating level of consciousness, hyperthermia, muscular rigidity and autonomic instability.'

Neither droperidol nor metoclopramide have been implicated as causes of NMS. A case of coma following the use of parenteral droperidol for post-ECT confusion

\section{Key words}

ANAESTHETICS, INTRA VENOLS: droperidol; PHARMACOLOGY: metoclopramide, droperidol; COMPLICA TIONS: neuroleptic malignant syndrome.

From the Department of Anaesthesia, University of Manitoba, Health Sciences Center, Winnipeg: Manitoba R3E 0Z3.

Address correspondence to: Dr. Patel. has been reported. ${ }^{2}$ Although droperidol-induced NMS was considered in the differential diagnosis, the patient did not manifest all of the classical clinical features of NMS. Fever associated with metoclopramide-induced dystonias has been reported in two cases. ${ }^{3}$ In both these cases, NMS was not entertained in the differential diagnosis. We describe a case of NMS following the use of droperidol in conjunction with metoclopramide and discuss the diagnostic challenge such a case presents to anaesthetists.

\section{Case report}

A healthy 23 -year-old male (weight $100 \mathrm{~kg}$ ) suffering from recurrent dislocations of his right shoulder was admitted to the hospital on the day before surgery for an elective Putti-Platt repair and capsulotomy of his right shoulder. He was seen by the attending anaesthetist on the day prior to surgery and judged to be fit for surgery and was classified as ASA physical status I. He had had a prior general anaesthetic complicated by postoperative nausea and vomiting. He denied a family history of problems with anaesthesia.

Morphine $10 \mathrm{mg}$ IM was administered one hour preoperatively. Anaesthesia was induced with fentanyl $100 \mu \mathrm{g}$ IV, thiopentone $350 \mathrm{mg}$ IV and succinylcholine $120 \mathrm{mg}$ IV and was maintained with oxygen, nitrous oxide and halothane. Fentanyl (total dose of $150 \mu \mathrm{g}$ ) was administered as required. Pancuronium $3 \mathrm{mg}$ was administered for muscle relaxation. Metoclopramide $10 \mathrm{mg}$ IV and droperidol $5 \mathrm{mg}$ IV were administered intraoperatively, because of the history of postoperative nausca and vomiting. Following completion of the surgical procedure, the muscle relaxation was reversed with atropine $1.2 \mathrm{mg}$ IV and neostigmine $2.5 \mathrm{mg}$ IV. The patient was extubated while in the lateral decubitus position and transported to the postanaesthesia recovery room (PARR).

Upon arrival in the PARR, the patient's vital signs were normal. Nasal oxygen was administered. He was somnolent and unresponsive to verbal commands. He demonstrated nonpurposeful and random movements of his extremities. Muscle tone was noted to be moderately 
TABLE Arterial blood gas results

\begin{tabular}{lllllllll}
\hline Time posi-op $(h)$ & $\mathrm{FHO}_{2}$ & $\mathrm{PaO}_{2}$ & $\mathrm{PaCO}_{2}$ & $\mathrm{pH}$ & $\begin{array}{l}\mathrm{HCO} \\
(\mathrm{mEq})\end{array}$ & $\begin{array}{l}\mathrm{BE} \\
(\mathrm{mEq})\end{array}$ & $\begin{array}{l}\text { Temp } \\
\left({ }^{\circ} \mathrm{C}\right)\end{array}$ & Comments \\
\hline 3.75 & & 114 & 46 & 7.30 & 22 & & & Nasal oxygen \\
10.50 & & 84 & 25 & 7.22 & 10 & -14.9 & 39.5 & Mask oxygen \\
10.60 & 1.0 & 159 & 49 & 7.13 & 16 & -12.9 & 39.5 & Intubated \\
15.50 & 0.7 & 268 & 24 & 7.47 & 17 & -3.3 & 38.2 & \\
19.50 & 0.4 & 114 & 38 & 7.39 & 23 & -1.0 & 37.0 & \\
\hline
\end{tabular}

increased. His skin was flushed and he was diaphoretic. Respirations were normal. His blood pressure and pulse were labile and fluctuated from $120 / 80 \mathrm{mmHg}$ to $180 / 120 \mathrm{mmHg}$ and $100-180$ beats $\mathrm{min}^{-1}$ respectively. Serum electrolytes, blood glucose and arterial blood gas determinations were normal. Three hours following admission to the PARR the patient's status had remained unchanged. Naloxone $0.4 \mathrm{mg}$ IV was given without any effect. As some of the signs demonstrated by the patient suggested idiosyncratic anticholinergic effects, the patient was given physostigmine $1 \mathrm{mg} I \mathrm{~V}$, which also was ineffective. With the possibility that the patient was suffering from the extra-pyramidal side effects of droperidol and or metoclopramide, ${ }^{4}$ benztropine $1 \mathrm{mg}$ IV was given, without effect.

Seven hours postoperatively the patient had not improved. The rectal temperature at that time was $38.4^{\circ} \mathrm{C}$. A neurological consultation was sought but a diagnosis was not made. The patient was subsequently admitted to the Intensive Care Unit for further observation and menitoring.

In the ICU, the patient's status deteriorated. He became hypertensive (BP 222/86 $\mathrm{mmHg}$ ) and tachycardic (pulse $160-180$ beats. $\min ^{-1}$ ). He was flushed and profusely diaphoretic. His skin was mottled over the trunk. The patient was tachypnoeic with a respiratory rate of about $30-40$ breaths $\mathrm{min}^{-1}$. The rectal temperature rose to more than $40^{\circ} \mathrm{C}$, over an hour. He remained obtunded and was not responsive to painful stimuli. The extremities, trunk and neck were rigid and the eyes were deviated to the left. No overt seizure activity was noted.

Oxygen was administered by a face mask. An arterial line was established and normal saline infused intravenously. An initial artcrial blood gas sample revealed a moderate metabolic acidosis. The results of arterial blood gas determinations are shown in the Table. Fifty $\mathrm{mEq}$ of sodium bicarbonate were administered. Dantrolene $2 \mathrm{mg} \cdot \mathrm{kg}^{-1}$ (total dose $200 \mathrm{mg}$ ) administration was started. Mannitol $12.5 \mathrm{~g}$ was given intravenously. After the first dose of dantrolene $(20 \mathrm{mg})$, a priming dose of atracurium (10 mg) was given followed by $30 \mathrm{mg}$ IV which rapidly resulted in profound muscle relaxation. The patient was intubated and mechanically ventilated. The remaining dantrolene was subsequently given. Paralysis was maintained with pancuronium as needed and the patient was sedated with morphine and diazepam.

The patient was placed on a cooling blanket. He was covered with a water-soaked blanket on which ice was placed. With these measures, the temperature was rapidly controlled and it decreased to $38^{\circ} \mathrm{C}$ (oesophageal) within one hour.

A computerized tomographic scan of the brain performed shortly after admission to the ICU was normal. A lumbar puncture was performed; the CSF was normal. On the following day, an EEG showed diffuse slow wave activity most likely secondary to a metabolic dysfunction. Cultures of the blood, urine, endotracheal tube aspirate and CSF were negative. Laboratory results showed a leukocytosis with a left shift Creatine kinase level, drawn 18 hours following admission to the $\mathrm{ICU}$, was elevated to 2168 units, urea $2.4 \mathrm{mmol}^{-\mathrm{L}^{-1}}$, creatinine $0.08 \mathrm{mmol}$. $\mathrm{L}^{-1}$. There was no gross evidence of myoglobinuria.

On the second postoperative day, the patient's status had improved considerably. He was oriented and responded appropriately. There were no focal neurological signs. His temperature had decreased to $37.5^{\circ} \mathrm{C}$. He was then extubated and discharged to the ward where his recovery continued uneventfully. He was provided with a Medic-alert bracelet waming of his sensitivity to neuroleptics. He was discharged from the hospital on the tenth postoperative day without obvious sequelae.

\section{Discussion}

The NMS was first described by Delay and Daniker in $1968 .{ }^{5}$ Since its original description, NMS has been the subject of many reviews. ${ }^{1,6-9}$ NMS has been estimated to occur in $0.5-1.0$ per cent of all patients exposed to neuroleptics. It predominantly affects young men. Phenothiazines, butyrophenones, thioxanthenes and the newer antipsychotic agents such as loxapine have been associated with the development of NMS. The ability of an antipsychotic agent to precipitate NMS appears to be related to its antidopaminergic potency. Clinical features of the syndrome include hyperthermia, rigidity of skeletal muscles, autonomic imbalance and fluctuating level of consciousness which ranges from random nonpurposeful 
movements, mutism and confusion to coma. NMS usually develops in one to three days following exposure and can last up to ten or more days. Mortality from NMS has been estimated at about 20-30 per cent. Abnormal laboratory results, while not specific for NMS, include leukocytosis, elevated liver function tests and creatine kinase. This case presented a diagnostic challenge. Prior to the development of the full syndrome, a number of possible diagnoses were entertained. The patient had received $10 \mathrm{mg}$ of morphine preoperatively and a total of $250 \mu \mathrm{g}$ of fentanyl during anaesthesia. The failure of naloxone to improve the patient's level of consciousness suggests that his condition was not related to narcotization.

Antipsychotic drugs, including droperidol, are known to cause extra-pyramidal side effects which include a generalized increase in muscle tone. ${ }^{5}$ In addition, metoclopramide has been reported to cause a parkinsonian syndrome and tardive dyskinesia in elderly patients or young patients receiving large doses. ${ }^{4}$ Metoclopramideinduced extrapyramidal disorder has been recently described following the use of preoperative metoclopramide. ${ }^{10}$ These effects can be rapidly improved with the administration of anticholinergic drugs. Our patient had received both droperidol and metoclopramide; the muscular rigidity could have been caused by these agents. However, the failure of benztropine to improve the patient's condition does not favour this diagnosis.

Anticholinergic drugs, including the neuroleptics, can produce the central anticholinergic syndrome. ${ }^{1}$ Clinical features of this syndrome include confusion and disorientation, dry flushed skin, dilated pupils, urinary retention and a mildly elevated temperature. Although our patient demonstrated some of these features, the fact that he was profusely diaphoretic and the failure of physostigmine to reverse them argue against this diagnosis.

Malignant hyperthermia ( $\mathrm{MH})$ is well known to anaesthetists. Although the onset of MH can be acute, it frequently manifests in the recovery room and can be delayed for several hours. MH was strongly considered in the differential diagnosis. Defective membrane regulation of calcium transport is thought to be the cause of muscle contraction and rigidity. On the other hand, NMS appears to be of central and presynaptic origin. ' Whereas muscle relaxants are effective in producing muscle relaxation in NMS, they fail to do so in MH. Our patient received both dantrolene and muscle relaxants; however, he had received only $20 \mathrm{mg}$ of dantrolene prior to the use of muscle rclaxants, a dose insufficient to decrease muscle rigidity of MH. The time course of events suggests that muscle relaxation was produced by atracurium rather than the dantrolene. Retrospectively, this case demonstrates all the classical findings of NMS. Furthermore, the profound neurological signs in the abscence of, initially, fever and acidosis supports the diagnosis of NMS rather than of $\mathrm{MH}$.

NMS presumably is precipitated by central dopamine receptor blockade. Both droperidol and metoclopramide have central antidopaminergic effects. ${ }^{4}$ In addition, fever associated with metoclopramide-induced dystonia has been reported. ${ }^{3}$ In both the cases reported, the dystonias responded rapidly to the anticholinergic agent procylidine whereas the fever subsided within 24 hours. The patients' level of consciousness was not commented on. NMS was not entertained in the differential diagnosis. However, the authors did suggest that the fever may have been a manifestation of the central nervous system toxicity of metoclopramide, which may involve blockade of dopamine receptors. In our patient, the muscular rigidity did not respond to benztropine. This favours the diagnosis of NMS. Thus, NMS in our patient may have been precipitated by metoclopramide, droperidol or a combination of the two drugs. Since potentiation of antidopaminergic effects may occur with metoclopramide, its use in conjunction with other antidopaminergic agents is not recommended.

As NMS is an uncommon disorder, no controlled studies regarding its treatment have been published. Since NMS is precipitated by anti-dopaminergic agents, several case reports have documented the effectiveness of dopamine agonists. Bromocriptine in doses of 2.5 to $10 \mathrm{mg} P O$ tid has been effective as has amantidine (a dopamine agonist) in doses of $100 \mathrm{mg}$ PO bid. Based upon its use in $\mathrm{MH}$, dantrolene has also been recommended for NMS. By producing muscular relaxation, dantrolene can reduce body temperature and oxygen consumption. The intravenous dose has ranged from 0.8 to $10 \mathrm{mg} \cdot \mathrm{kg}^{-1}$.'

While the primary problem in NMS is thought to be central thermoregulatory dysfunction, thermogenesis is primarily due to muscular rigidity. ${ }^{7}$ Muscle relaxants are effective in producing muscular relaxation in NMS; this suggests another mode of treatment which, to our know]edge, has not been reported before. We used atracurium to provide rapid muscle relaxation in our patient. Once the patient was paralyzed and ventilated, we were able to rapidly reduce his body temperature. Within an hour after muscle relaxation, the temperature had fallen and the patient had become haemodynamically more stable. Although this did not affect his neurologic status, it proved to be effective symptomatic and supportive treatment.

In summary, NMS is an uncommon disorder precipitated by neuroleptic drugs, including some commonly used by anaesthetists. It is characterized by hyperthermia, altered level of consciousness, muscular rigidity and autonomic imbalance. It has a significant mortality. To date, dantrolene, bromocriptine and amantadine have 
been reported to be effective. Muscle relaxants can now be added to this list.

\section{References}

1 Guze $B H$, Baxter $L R$. Neuroleptic malignant syndrome. N Engl J Med 1985; 313: 163-6.

2 Koo JYM, Chien CP. Coma following ECT and intravenous droperidol: case report. J Clin Psych 1986; 47 : 94-5.

3 Wandless I, Grimley Evans J, Jackson $M$. Fever associated with metoclopramide-induced dystonia. Lancet 1980; 1: 1255-6.

4 Grimes ID, Hassan MN, Preston DN. Adverse neurologic effects of metoclopramide. Can Med Assoc J 1982; 126: 23.

5 Delay J, Diniker P. Drug-induced extrapyramidal syndromes. In: Vinken PJ, Bruyn GW (Eds.). Handbook of Clinical Neurology. Vol 6. Diseases of Basal Ganglia. Amstendam: North Holland Publishing, pp 248-66. 1968.

6 Abbott RJ, Loizon LA. Neuroleptic malignant syndrome. Br J Psych 1986; 148: 47-51.

7 Gibb WRG, Lees $A J$. The neuroleptic malignant syndrome - a review. Quart J Med 1985; 56: 421 -9.

8 Smego RA, Durack DT. The neuroleptic malignant syndrome. Arch Intern Med 1982; 142: $1183-5$.

9 Levenson JL. Neuroleptic malignant syndrome. Am J Psych 1985; 142: 1137-45.

10 Scheller MS, Sears $K L$. Postoperative neurologic dysfunction assaciated with preoperative administration of metoclopramide Anesth Analg 1987; 66: 274-5.

\section{Résumé}

On présente un cas de syndrome neuroleptique malin en période postopératoire. Un homme de 23 ans en bon étot général a subi, sans incident une capsulotomie d' une épaule sous anesthesie au fentanyl, à l'halothane, au protoxyde d'azote et da l'oxygène. Afin de prévenir une nausée postopératoire, on lui a donné $5 \mathrm{mg}$ de dropéridol $\mathrm{N}$ et $10 \mathrm{mg}$ de métocolopramide $I V$ en période intraopératoire. En période postopératoire, une instabilité autonome, une fiève et une rigiditê musculaire généralisée se manifesta chet le patient. Son niveau de conscience s'affaissa. Ces constatations étaient compatibles avec le diagnastic d'un syndrome neuroleprique malin Le traitement de support pour le patient comprenait des mesures actives de refroidissement, de la relaxation musculaire et de la ventilation mécanique. On discute de l'habileté des agents antidopaminergiques, y compris te métoclopramide et le dropéridal. à précipiter le syndrome neuroleptique malin. On discute brièvement du traitement du syndrome neuroleptique malin. 